\title{
CORRESPONDENCE.
}

\section{ON THE METHOD OF DERIVING FROM A TABLE OF PREMIUMS THE RATE OF MORTALITY ON WHICH IT IS BASED.}

To the Editor of the Assuranee Magazine.

Sir,-I have looked over several prospectuses of Assurance Companies lately, and have been pazzled in some cases to find out the table of mortality according to which the annual premiums have been calculated throughout. Either the pure premiums have been loaded capriciously, or the premium tables have been meddled with by unskilful hands, in some instances; or, possibly, many Offices have their own particular tables of mortality, which are not made known to the world; or perhaps there may be some whose dexterity has enabled them to graduate a table of premiums irrespective of any table of mortality whatever.

I shall therefore assume that a table of pure premiums is given, to find out the table of mortality upon which it is based.

Let $p_{m}$ and $p_{m+1}$ be the pure premiums for any two consecutive ages; $a_{m}, a_{m+1}$, the present values of annuities corresponding to these ages; $l_{m}, l_{m+1}$, the numbers living, and which are to be registered in the table songht; $v=\frac{1}{1+r}$ and $d=1-v . \quad$ Then (1), $p_{m}=\frac{1}{1+a_{m}}-d$; $p_{m+1}=\frac{1}{1+a_{m+1}}-d$; also (3), $a_{m n}=\frac{l_{m+1} v}{l_{m}}\left(1+a_{m+1}\right)$. By means of these three equations the values $a_{m}$ and $a_{m+1}$ may be eliminated thus-

Hence

$$
\begin{gathered}
p_{m+1}-p_{m}=\frac{1}{1+a_{m+1}}-\frac{1}{1+a_{m}} \text { from }(3) \frac{1}{1+a_{m+1}}=\frac{l_{m+1} v}{l_{m} a_{m}} \\
\therefore p_{m+1}=\frac{l_{m+1} v}{l_{m m} a_{m s}}-d, \text { and } a_{m}=\frac{v-p_{m}}{d+p_{m}} .
\end{gathered}
$$

$$
p_{m+1}+d=\frac{l_{m+1} v}{l_{m}} \cdot \frac{d+p_{m}}{v-p_{m}}, \text { or } \frac{\left(p_{m+1}+d\right)\left(v-p_{m}\right) l_{m}}{v\left(d+p_{m}\right)}=l_{m+1},
$$

in which $l_{m}$ may be assumed arbitrarily. Suppose $l_{m}=l_{10}$, then $l_{10}$ being made equal to any convenient number, $l_{11}, l_{12}, l_{13}$, \&c. may be found throughont.

If $l_{10}=6460$, then $p_{10}=\cdot 0116702 ; p_{11}=\cdot 0119812 ; d=\cdot 0291260$; $v=.9708740 \therefore l_{11}=\frac{(.0411072)(\cdot 9592038)(6460)}{(.0407962)(\cdot 970874)}=6431$, as in the Carlisle Table.

GEO. SCOTT.

40, King William Street, London Bridge, 14th April, 1856.

Note.-A communication from Mr. William Wylie on this subject will be found at page 391 , vol. ii., of this Journal.-ED. A. $M$. 